\title{
Time-Varying Linkages of Economic Activities in China and the Stock Markets in ASEAN-5
}

\author{
Kee Tuan Teng', Siew Hwa Yen², Soo Y. Chua ${ }^{2}$, Hooi Hooi Lean ${ }^{2}$
}

\begin{abstract}
This study attempts to investigate the evolution of dynamic linkages and volatility spillover between the five countries of the Association of Southeast Asian Nations (ASEAN-5) stock markets and China's economic activities. By using the movements and structural breaks of the time-varying correlation and Granger causality test, a suitable destination for equity portfolio diversification can be determined among the studied markets. This study covers monthly data from January 1991 to March 2015. The DCC-MGARCH model shows that the studied countries are time-varying correlated, while the structural break observed by Bai and Perron test coincided with major economic shocks, policy changes and the establishment of regional trade policies. The VAR model Granger causality test observed no volatility spillover from Chinese economic activities to the ASEAN-5 stock markets, except for Malaysia and the Philippines. However, the ASEAN-5 stock markets' volatility exerts a significant influence on China's economy, except for Singapore's stock market volatility. This study reveals that ASEAN-5 has gradually became the preferred destination for diversifying equity portfolios for investors in China.
\end{abstract}

KEY WORDS: $\quad$ ASEAN, China, financial integration, volatility spillover

JEL Classification: F15, F36

${ }^{1}$ Tunku Abdul Rahman University College, Malaysia; ${ }^{2}$ Universiti Sains Malaysia, Malaysia

\section{Introduction}

Over the past two decades, China has played a growing and significant role in global trade. By 2011, China became either the largest or second-largest trading partner to 78 countries, which accounted for almost 55 per cent of the global GDP. These countries include all major global economies - the EU, the U.S., the Association of Southeast Asian Nations (ASEAN), Japan and India. ${ }^{1}$

\section{-}

Correspondence concerning this article should be addressed to: Hooi Hooi Lean, Universiti Sains Malaysia - Economics Program. School of Social Sciences Universiti Sains Malaysia USM Penang 11800, Malaysia T:604-6532663 E-mail: hooilean@usm.my
Although China claimed to be immune from crises in Asia, particularly the Asian Financial crisis, the late 2007 financial crisis that originated in the U.S. has an apparent impact on the future prospects of Asian economies, including China. The Chinese GDP growth rate plunged from $14.2 \%$ in 2007 to $9.6 \%$ in 2008 , and it has not experienced a double-digit growth rate since then. This condition has a varying impact on various industries and its trading partners as a reduction in investments and infrastructure spending causes downward pressure for China's demand. This has been a major concern for ASEAN-5 investors; the impact of China's economic slowdown could be felt around the world. ${ }^{2}$ It is also important to note that China has experienced 
miraculous economic growth without any recessions since the last trough in December 1989. ${ }^{3}$ As an emerging economy, investors may also speculate about the possibility that volatility in the ASEAN-5 stock markets could be transmitted to China's economy.

As such, it is appropriate for us to look at the dynamic cross-country volatility transmission across ASEAN-5 stock markets with China's economic movements. This study examines the time-varying crosscountry correlation movements between the ASEAN-5 stock markets and the economic activities in China using the Dynamic Conditional Correlation Multivariate GARCH (DCC-MGARCH) model (Engle, 2002). We identify the structural breaks dates in the time-paths of the dynamic conditional correlation using the Bai and Perron (2003) multiple structural break test. This procedure could detect sudden changes in the nature of the cross-market co-movement. This study also explores the possibility of stock portfolio diversification among the studied markets using the Granger causality, which is based on the vector autoregression (VAR) model, to capture the direction of the time-varying volatility transmission. One should note that crosscountry linkages are gaining importance to investors and policy makers. It would be insightful to assess the changing direction of the volatility spillover among the relevant countries with the rise of China in the global economic context.

This paper contributes to the existing literature by addressing the chicken-and-egg paradox that existed in the relationship between stock market volatility and economic movement volatility. This study also attempts to fill the gap in investigating the interaction between emerging economies caused by the ASEAN-5 stock market performance and Chinese economic growth in a time-varying manner and provides some noteworthy insights into the aspect of the volatility spillover direction across stock markets and economic activity movements in a multi-country context. We hope that our findings may shed some light on international asset diversification and management in ASEAN-5 and China, serving as a constructive guide to investors in determining the appropriate portfolio channel for equity market diversification.

The remainder of this study is structured as follows: Section 2 examines the portfolio diversification literature, and Section 3 presents the methodology and de- scribes the data. The results are reported in Section 4, and the last section concludes the study.

\section{Literature Review}

Studies in the international diversification of assets have generated interest among academics and investors in ASEAN-5 because the ASEAN-5 stock markets are becoming more financially integrated over time (Candelon, Piplack, \& Straetmans, 2008; Lim, 2009; Majid et al., 2009; Plummer \& Click, 2005). It is vital to understand the concept of portfolio management prior to the discussion on the allocation of assets in international markets.

The modern portfolio theory was proposed by Markowitz (1952). According to this theory, risk-averse investors optimize the return on their investments by diversifying the portfolio of assets with negative correlations. This means that low and negative correlations among assets will offer gains in diversification (Hassan \& Naka, 1996; Laopodis, 2005). High correlations, high volatility spillover and highly synchronized movements among the stock markets implied limited opportunity for risk diversification among the correlated and synchronized assets (Bekaert \& Harvey, 1997). However, the rise in correlation among financial markets does not necessarily increase volatility in the domestic market (Bekaert \& Harvey, 1997). It may be concluded that a high level of market integration reduces the possibility of risk sharing in the asset portfolio among these markets.

One should note that market integration shows a dynamic trend and changes over time (Gupta and Donleavy, 2009). The level of interdependency between countries changes gradually over time with trade and financial liberalization, the formation and implementation of regional trade arrangements, and information technology breakthroughs (Guillaumin, 2009; Harvey, 2000; Hooy \& Goh, 2010; Laopodis, 2005). Aside from this, a regime change in the financial market of an emerging economy is prone to stimulation by the rise of market integration between countries (Bekaert \& Harvey, 2002).

The diversification of assets is, in fact, a risk management method that intends to minimize the risk of the selected portfolio while maximizing the return of the portfolio (Vo \& Daly, 2005). This can be done by combining a broad selection of investments with 

Table 1. Descriptive Statistics (January 1991-March 2015)

\begin{tabular}{lcccccc}
\hline & CH & JSE & KLCI & PSE & SSI & THSE \\
\hline Mean (\%) & $-0.02 \%$ & $0.87 \%$ & $0.45 \%$ & $0.86 \%$ & $0.45 \%$ & $0.30 \%$ \\
Std. Dev. (\%) & $3.63 \%$ & $7.43 \%$ & $6.42 \%$ & $7.28 \%$ & $5.36 \%$ & $8.25 \%$ \\
Skewness & -0.4713 & -1.0388 & 0.1899 & 0.3531 & -0.0937 & -0.2187 \\
Excess Kurtosis & $9.4996^{* * *}$ & $3.2744^{* * *}$ & $4.8376^{* * *}$ & $5.5854^{* * *}$ & $2.6660^{* * *}$ & $2.0196^{* * *}$ \\
Jarque-Bera & $1104.963^{* * *}$ & $182.3368^{* * *}$ & $285.4978^{* * *}$ & $384.3072^{* * *}$ & $86.60244^{* * *}$ & $51.77549^{* * *}$ \\
Q(12) & $111.955^{* * *}$ & $37.3921^{* * *}$ & $66.4097^{* * *}$ & $3.9402(1)^{* *}$ & $26.4219^{* * *}$ & 13.3635 \\
ARCH, Q2(12) & $91.3329^{* * *}$ & $76.2439^{* * *}$ & $270.257^{* * *}$ & $8.44705(2)^{*}$ & $59.3143^{* * *}$ & $126.425^{* * *}$ \\
ADF (Level) & $-0.3871(3)$ & $2.6211(1)$ & $0.6335(2)$ & $2.6120(0)$ & $0.9663(0)$ & $0.3284(0)$ \\
ADF (1st dif) & $-16.35623(2)^{* * *}$ & $-7.3230(2)^{* * *}$ & $-9.3173(1)^{* * *}$ & $-16.0728(0)^{* * *}$ & $-14.7203(0)^{* * *}$ & $-16.5551(0)^{* * *}$ \\
\hline
\end{tabular}

Notes: Lag length is given in parentheses. ${ }^{* *},{ }^{* *},{ }^{*}$ indicate significance at $1 \%, 5 \%$ and $10 \%$, respectively. For the ADF test, MAXLAG $=14$

Automatic is based on SIC.

China's industrial production index was negative but almost close to zero for China. The standard deviation for economic activity in China was below 5.5 percent, which implies that the risk of economic turbulence was low in China, indicating a stable economy over time. China's industrial production index displayed negative skewness and positive excess kurtosis, which indicates a leptokurtic distribution.

The ASEAN-5 stock markets' average market return and risk are shown by the mean and standard deviations of the monthly return series, respectively. The ASEAN-5 stock markets have higher volatility with moderate returns compared to economic movements in China. This implies that ASEAN-5 stock markets could have high inherent risk. Most stock returns in this study show negative skewness except for Malaysia and the Philippines. This suggests a high probability of positive returns in Malaysian and Philippines' stock market investment. All ASEAN-5 stock market returns had a leptokurtic distribution, which implies that the stock markets may generate either very large or very small future returns. This is shown by the positive excess kurtosis implicating high volatility in these stock markets' investments.

The Jarque-Bera test statistics strongly reject the hypothesis of normality, which implies that all return series are not normally distributed. The Engle (1982) $\mathrm{ARCH}$ test rejects the null hypothesis of no $\mathrm{ARCH}$ effects for all stock return series. The results justified the choice of the GARCH model. The autocorrelation patterns in the return series was examined using the Ljung-Box test. The Q statistics test results are significant at lag 12 for all series except for the stock market index for the Philippines at lag 1 . The stock market index for Thailand is insignificant for Q statistics. The first order autocorrelations are low; hence, the first-order autoregressive process, $\mathrm{AR}(1)$, needs to be included in the mean equation of the GARCH $(1,1)$ model (Arouri \& Nguyen, 2009; Hamilton \& Gang, 1996).?

\subsection{Dynamic Conditional Correlation - Multivariate Generalized Autoregressive Conditional Heteroscedasticity Model}

Unlike the previous studies that focus on interactions between stock markets, this paper employs the DCCMGARCH model to evaluate the volatility and co-volatility dynamics across multiple countries' stock markets and Chinese economic activities. One of the key advantages of this model is the number of parameters generated in the dynamic structures of the conditional correlation, and the covariance matrices reduced as the model dimensions increased. This overcomes the main 
weaknesses of other MGARCH models (Engle, 2000). Hence, this multivariate model is superior to other methods and produces the most accurate estimators (Engle, 2000).

The DCC-MGARCH model is used in this study to evaluate changes in economic interdependency as it can capture the degree of volatility correlation changes between two countries in a time-varying manner. The extent of market integration is indicated by the time-varying conditional correlation (dynamic conditional correlation), whereas its trend can be gauged by the patterns of conditional correlation movements. Markets are said to become more integrated when conditional correlations increase over time (Yu, Fung, \& Tam, 2010). Conditional correlations can also infer whether two economies are decoupling or recoupling over time. For example, two economies are viewed as decoupling when the conditional correlation falls over time. A high conditional correlation between two stock markets can also indicate less opportunity for diversification.

The DCC-MGARCH model (Engle, 2002) generates the volatility correlation between two markets either directly through its conditional variance or indirectly through its conditional covariances. The conditional covariances generated show the time-variant crossmarket volatility correlation or the dynamic conditional correlation.

The DCC-MGARCH model is a dynamic model with the time-varying means, variances and covariances of the $n$ return series, $r_{i, t}$ for country $i$ at time $t$ with the equations as follows:

$r_{i, t}=\mu_{i, t}+\varepsilon_{i, t} \quad \varepsilon_{i, t} \mid \Psi_{t-1} \sim N\left(0, \mathrm{H}_{\mathrm{t}}\right)$

where $\Psi_{t-1}$ is the set of information available at times $\mathrm{t}-1$ that contains at least $\left\{r_{i, t-1}, r_{i, t-2}, \ldots\right\}$.

Each individual country's return series follows an autoregressive process (Arouri and Nguyen, 2009; Hamilton and Gang, 1996). The conditional mean equation of the return series for country $i$ is written as $\mu_{i, t}=$ $\lambda_{0}+\lambda_{1} r_{i, t-1}$, where $\lambda_{0}$ is a constant term, and $\lambda_{1}$ is the coefficient of the lagged return for each market.

The conditional variance-covariance matrix for the DCC-MGARCH model is written as $H_{t}=D_{t} R_{t}$ $D_{t}$, where $H_{t}$ is also denoted as the conditional correlation estimator, $R_{t}$ of the DCC model is a $(n \times n)$ time-varying conditional correlation matrix, and the conditional variance must be unity, while $D_{t}$ is a $(n \times n)$ diagonal matrix of time-varying standard deviations of the returns in the mean equation from the univariate GARCH $(1,1)$ model. $^{8}$

$D_{t}$ for a multivariate model is expressed as $D_{t}=\operatorname{diag}\left(\sqrt{h_{1, t}}, \ldots, \sqrt{h_{n, t}}\right)$ with $h_{i, t}=\tau_{i}+\alpha_{i} \varepsilon_{i, t-1}^{2}+\beta_{i} h_{i, t-1}$, where $\tau_{i}$ is a constant term for the conditional variance equation for country $i, \alpha_{i}$ is the ARCH effect of the return series, while $\beta_{i}$ is the GARCH effect of the return series. A positive coefficient of $\beta_{i}$ implies volatility clustering and persistence in positive changes in stock market indices. A sum of $\alpha_{i}$ and $\beta_{i}$ that is less than 1 indicates the stationarity of the GARCH model and shows that the volatility shock is time-decaying and mean-reverting (Bollerslev, 1986). ${ }^{9}$ The $R_{t}$ matrix contains the coefficients of the conditional correlation, which is given as $R_{t}=\operatorname{diag}\left(Q_{t}\right)^{-1} Q_{t} \operatorname{diag}\left(Q_{t}\right)^{-1}$, where $Q_{\mathrm{t}}$ is a $(n \times n)$ conditional covariance matrix that is a symmetric and positive definite, given by $Q_{t}=\left(1-\alpha_{d c c}+\beta_{d c c}\right) \bar{Q}+\alpha_{d c c}\left(\varepsilon_{t-1} \varepsilon_{t-1}^{\prime}\right)+\beta_{d c c} Q_{t-1}$, where $\bar{Q}$ denotes the unconditional covariances of the standardized errors matrix, which is a $(n \times n)$ symmetric positive definite matrix, and $\varepsilon_{t}=\left(\varepsilon_{1, t}, \ldots, \varepsilon_{n, t}\right)^{\prime}$ is the standardized residual terms. ${ }^{10}$ If $\left(\alpha_{d c c}+\beta_{d c c}\right)<1$, the model is mean reverting, but when $\left(\alpha_{d c c}+\beta_{d c c}\right)=1$, the model is said to be integrated.

Engel (2002) suggested the estimation of the timevarying conditional correlations $\left(q_{i j, j}\right)$ for any two return series included in $R_{t}$ by the following GARCH (1, 1) process.

$q_{i j, t}=\bar{\rho}_{i j}+\alpha_{d c c}\left(\varepsilon_{i, t-1} \varepsilon_{j, t-1}-\bar{\rho}_{i j}\right)+\beta_{d c c}\left(q_{i j, t-1}-\bar{\rho}_{i j}\right)$

where $\bar{\rho}_{i j}$ is the unconditional correlation between $\varepsilon_{i, t}$ and $\varepsilon_{j, t}$, and $\bar{q}_{i j, t}$ is the mean value of $q_{i j, t}$. The average variance is unity and the conditional correlation esti-

mator is. $\rho_{i j, t}=\frac{q_{i j, t}}{\sqrt{q_{i i, t} q_{j j, t}}}$ Hence, $\rho_{i j, t}$ for the $\operatorname{DCC}(1,1)$

can be rewritten as follows:

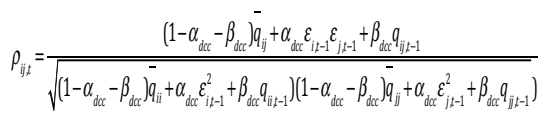

The significance of $\alpha_{d c c}$ and $\beta_{d c c}$ implies that the estimators obtained in the DCC-MGARCH are dynamic 
and time-varying. $\alpha_{d c c}$ measures the short-run volatility impact, which means that the persistency of the standardized residuals from the previous period. $\beta_{d c c}$ measures the lingering effect of a shock impact on the conditional correlations, which is the persistence of the conditional correlation process.

In this paper, the conditional correlation between the stock return series of country $i$ and the industrial growth rate series of country $j$ at time $t$ is referred to as $\left[R_{t,}\right]_{i j}=\rho_{i j, t}$, where $\rho_{i j, t}$ indicates the direction and strength of the correlation and measures the degree of covariance between two indices in relation to the market's individual variances (Savva, 2009). A positive $\rho_{i j, t}$ implies that the correlation between the return series is rising and moving in the same direction and vice versa.

\section{DCC-MGARCH Log Likelihood Estimation}

This study uses the Quasi-maximum likelihood (QML) estimation proposed by Bollerslev and Wooldridge (1992) for the estimation of the DCC-MGARCH model. ${ }^{11}$ The log-likelihood of the $H_{t}$ estimator can be written in the following forms:

$\mathrm{L}=-\frac{1}{2} \sum_{t=1}^{T}\left(n \log (2 \pi)+\log \left|H_{t}\right|+r_{i, t}^{\prime} H_{t}^{-1} r_{i, t}\right)$

The log-likelihood function consists of the volatility component, and correlation component can be expressed as $L(\theta, \Phi)=L_{v}(\theta)+L_{c}(\theta, \Phi)$, where $\theta$ is the parameter for $D_{t}$ and $\Phi$ is the additional parameter in $R_{t}$. The volatility component function can be written as

$$
L_{v}(\theta)=-\frac{1}{2} \sum_{t}\left(n \log (2 \pi)+\log \left|D_{t}\right|^{2}+r_{i, t}^{\prime} D_{t}^{-2} r_{i, t}\right),
$$

while the correlation component is written as

$$
L_{c}(\theta, \Phi)=-\frac{1}{2} \sum_{t}\left(\log \left|R_{t}\right|+\varepsilon_{t}^{\prime} R_{t}^{-1} \varepsilon_{t}-\varepsilon_{t}^{\prime} \varepsilon_{t}\right)
$$

Two-Stage Estimation of the DCC-MGARCH Model The DCC-MGARCH model estimation uses a twostage procedure. Under acceptable uniformity conditions, the second stage's consistency is dependent on the first stage's consistency. The univariate GARCH $(1,1)$ model for each return series in the multivariate system is estimated in the first stage. Standardized residuals are obtained by maximizing the likelihood, $\hat{\theta}=\arg \max \left\{L_{v}(\theta)\right\}$. The generated standardized re- siduals from stage 1 are then used to estimate the DCC parameters in stage 2 using the following equation:. $\max _{\Phi}\left\{L_{c}(\hat{\theta}, \Phi)\right\}$

\subsection{Bai and Perron Multiple Structural Break Test}

The BP multiple structural break test is applied to statistically investigate any structural changes that may have occurred in the conditional correlations between the ASEAN-5 stock return volatilities and the growth rate of economic movements in China. The actual economic event that coincided with the observed structural break dates explained the changes in the dynamic linkages between the pairs of countries.

The DCC series generated by the DCC-MGARCH model step 2 is used to detect the structural changes occurring naturally by employing the Bai and Perron (BP) (2003) multiple structural break test. It is not realistic to date only certain economic events and apply it to all pairs of countries in this study because each possible combination pair of countries may then face different economic events, which will impact them either as individual nations or jointly. In view of this, the conventional structural break test, such as the Chow structural break test, is not applicable in this study. The reason is that this test needs to set the structural break dates to test the significance of the events' impacts on the markets linkages. On the other hand, the Gregory and Hansen (1996) cointegration test with structural breaks is not applied in this research because it can only capture one break in the intercept and/or slope coefficient in the cointegrating relationships. The regime switching method is another commonly used approach in dating structural breaks, but it is relatively less powerful than the BP method (Bai \& Perron, 2003).

The Bai and Perron (BP) multiple structural break test has been adopted to estimate the number of break dates that happened naturally in the conditional correlations (Arouri \& Nguyen, 2009; Nguyen \& Bellalah, 2008)..$^{12}$ It is vital to identify the date of the structural changes in the financial market, which is induced by the advancement in market integration (Bekaert \& Harvey, 2002). This study followed the approach of Bekaert et al. (2002), which allows the structural break dates to narrate what is actually happening in the markets.

According to this method, the structural changes occurring naturally in the dynamic conditional cor- 

Table 2. DCC-MGARCH Step 1 Estimation Results for Full Sample (January 1991-March 2015)

\begin{tabular}{|c|c|c|c|c|c|c|}
\hline & JSE & $\mathrm{KLCl}$ & PSE & SSI & THSE & $\mathrm{CH}$ \\
\hline \multicolumn{7}{|c|}{ Mean Equation: AR(1) model: } \\
\hline Constant: $\lambda_{0}$ & $0.0119^{* * *}$ & $0.0068^{* * *}$ & $0.0133^{* * *}$ & $0.0063^{*}$ & $0.0110^{* * *}$ & -0.0012 \\
\hline $\operatorname{AR}(1): \lambda_{1}$ & $0.2012^{* * *}$ & 0.0920 & 0.1300 & $0.1735^{* *}$ & 0.0664 & -0.2790 \\
\hline \multicolumn{7}{|c|}{ Variance Equation: $\operatorname{GARCH}(1,1)$ model: } \\
\hline Constant: $\tau_{i}$ & $0.0005^{* * *}$ & 0.9421 & 2.2897 & $1.4216^{*}$ & $0.0006^{* *}$ & $4.1442^{* * *}$ \\
\hline $\mathrm{ARCH}: \alpha_{i}$ & $0.1358^{* *}$ & $0.2622^{* * *}$ & $0.1973^{*}$ & $0.1097^{* * *}$ & $0.3237^{* * *}$ & $0.7413^{* *}$ \\
\hline $\mathrm{GARCH}: \beta_{i}$ & $0.7599 * * *$ & $0.7366^{* * *}$ & $0.7744^{* * *}$ & $0.8342^{* * *}$ & $0.5962^{* * *}$ & -0.0122 \\
\hline$\alpha_{i}+\beta_{i}$ & 0.9611 & 0.9988 & 0.9717 & 0.9439 & 0.9200 & 0.7291 \\
\hline \multicolumn{7}{|c|}{ Robust Tests for model standardized residuals: } \\
\hline$Q(1)$ & $3.8589^{* *}$ & 1.3578 & 1.5834 & $24.9791(18)$ & 0.0045 & 1.1068 \\
\hline$Q^{2}(1)$ & 0.7241 & 0.3589 & 0.4313 & 0.9115 & 0.4923 & 0.0761 \\
\hline Skewness & $-0.7509^{* * *}$ & $0.2983^{* * *}$ & $0.0120^{* * *}$ & $-0.1661^{* * *}$ & $0.1611^{* * *}$ & $0.4311^{* * *}$ \\
\hline Excess Kurtosis & $2.8942^{* * *}$ & $1.7682^{* * *}$ & $1.9825^{* * *}$ & $1.185^{* * *}$ & $1.4112^{* * *}$ & $8.0630^{* * *}$ \\
\hline Jarque-Bera & $128.9100^{* * * *}$ & $42.2260^{* * *}$ & $47.6610^{* * *}$ & $18.3800^{* * *}$ & $25.4050^{* * *}$ & $797.2900^{* * *}$ \\
\hline
\end{tabular}

Remarks: Lag length: Automatic is based on SIC, MAXLAG $=14$. Lag length is given in parentheses. ${ }^{* * *},{ }^{* *},{ }^{*}$ indicate significance at 1\%,5\% and 10\%, respectively. UniGARCH for the A5-US model will be used as a comparison reference for all models. Only minor and insignificant differences exist in the results for all models.

The statistically insignificant results of these two tests indicate the absence of serial correlation and $\mathrm{ARCH}-$ effects in the conditional means and variances. The results of these two tests justified the employment of the DCC-GARCH specification for the selected countries, thus passing the misspecification tests.

Table 2 also reports the diagnostics of the standardized residuals. The skewness is positive for most stock return indices except for JSE and SSI. CH showed a high excess kurtosis of more than three. Thus, the level of risk for $\mathrm{CH}$ is low as the past returns yield a leptokurtic distribution. ${ }^{17}$ The JB test for normality strongly rejected the null hypothesis, which means that the indices do not follow a normal distribution. Hence, this suggests that the excess kurtosis in the residuals of the return indices were not fully eliminated by the conditionally normal GARCH process. Consequently, the diagnostics test justified the use of QML procedures in the estimation of the DCC-MGARCH model.

\section{Conditional Volatilities}

The monthly volatility of the ASEAN-5 stock markets and the industrial production growth rate for China, as measured by the conditional variances, are depicted in Figure 1. The volatility clustering in 1994 for JSE, KLCI, PSE and THSE can be explained by the aftermath effect of the unification of the exchange rate regime and the abolishment of exchange controls on the current account transactions in China. The volatility of stock returns in ASEAN-5 appeared to be affected most by 

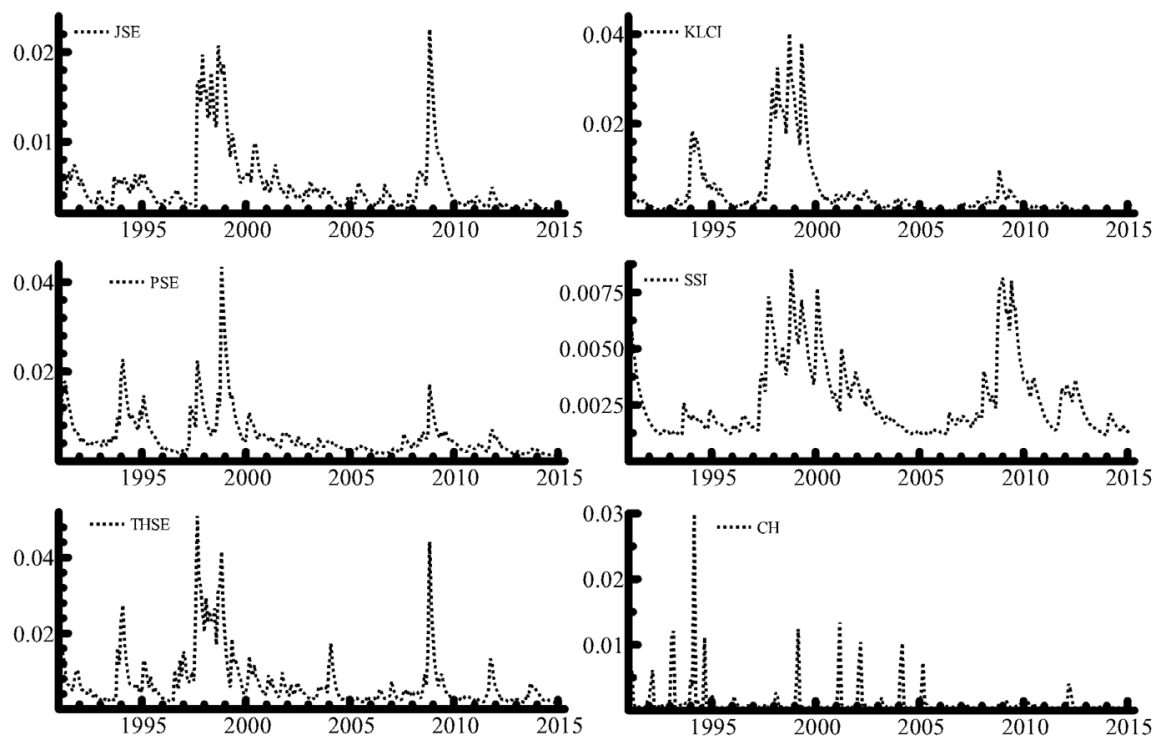

Figure 1. Conditional Variances of Stock Return for ASEAN-5 and Industrial Production Growth Rate for China

the Asian financial crisis from July 1997 until 2000, as shown in Figure 1, while the Chinese economy remained relatively calm and stable with only a sudden spike in 1999. The ASEAN-5 stock market conditional variances displayed a downward trend during the crisis period. However, during the subprime crisis, the ASEAN-5 stock return movements displayed a sudden surge in 2009, except in Malaysia. The stock return volatility in Singapore was more persistent during the occurrence of the subprime crisis compared to other ASEAN-5 stock return volatilities. The most noticeable feature from Figure 1 is the tendency for the volatility to cluster. The figures for the conditional variance for the ASEAN-5 stock returns suggest the existence of ARCH-GARCH effects.

The plot for China's industrial production growth rate was consistently volatile throughout the sample, especially at the beginning of the sample period. The Chinese economy was more volatile and surged to a peak between the late 1990s and 2005. After 2006, the volatility in the industrial production growth rate in
China began to stabilize with very small clustering. There is a small surge in early 2012. The graphs in Figure 1 served as indicators of the presence of $\mathrm{ARCH}$ GARCH effects.

\subsection{The DCC-MGARCH - Time-Varying Patterns for ASEAN-5 Stock Markets with the Chinese Economic Activities}

Table 3 reports the time-varying co-movement between the ASEAN-5 stock markets with the economic movements in China. The DCC- $\alpha$ and DCC- $\beta$ are significant, which imply that ASEAN-5 stock returns with the industrial production growth rate for China were highly dynamic and time varying. The DCC- $\beta$ indicates the high persistence in the dynamic conditional correlation of stock returns of ASEAN-5 with China's economic activities. The sum of the DCC- $\alpha$ and DCC- $\beta$ are less than one, which indicates that the conditional correlations in the models are not constant over time, as reported in Table 3. 
Table 3. DCC-MGARCH Step 2 Estimation Results for Full Sample (January 1991-March 2015)

\begin{tabular}{ccc}
\hline$\alpha_{d c c}$ & $\beta_{d c c}$ & $\alpha_{d c c}+\beta_{d c c}$ \\
\hline $0.0291^{* * *}$ & $0.8610^{* * *}$ & 0.8900 \\
\hline
\end{tabular}

Remarks: ${ }^{* *},{ }^{* *},{ }^{*}$ indicate significance at $1 \%, 5 \%$ and $10 \%$, respectively

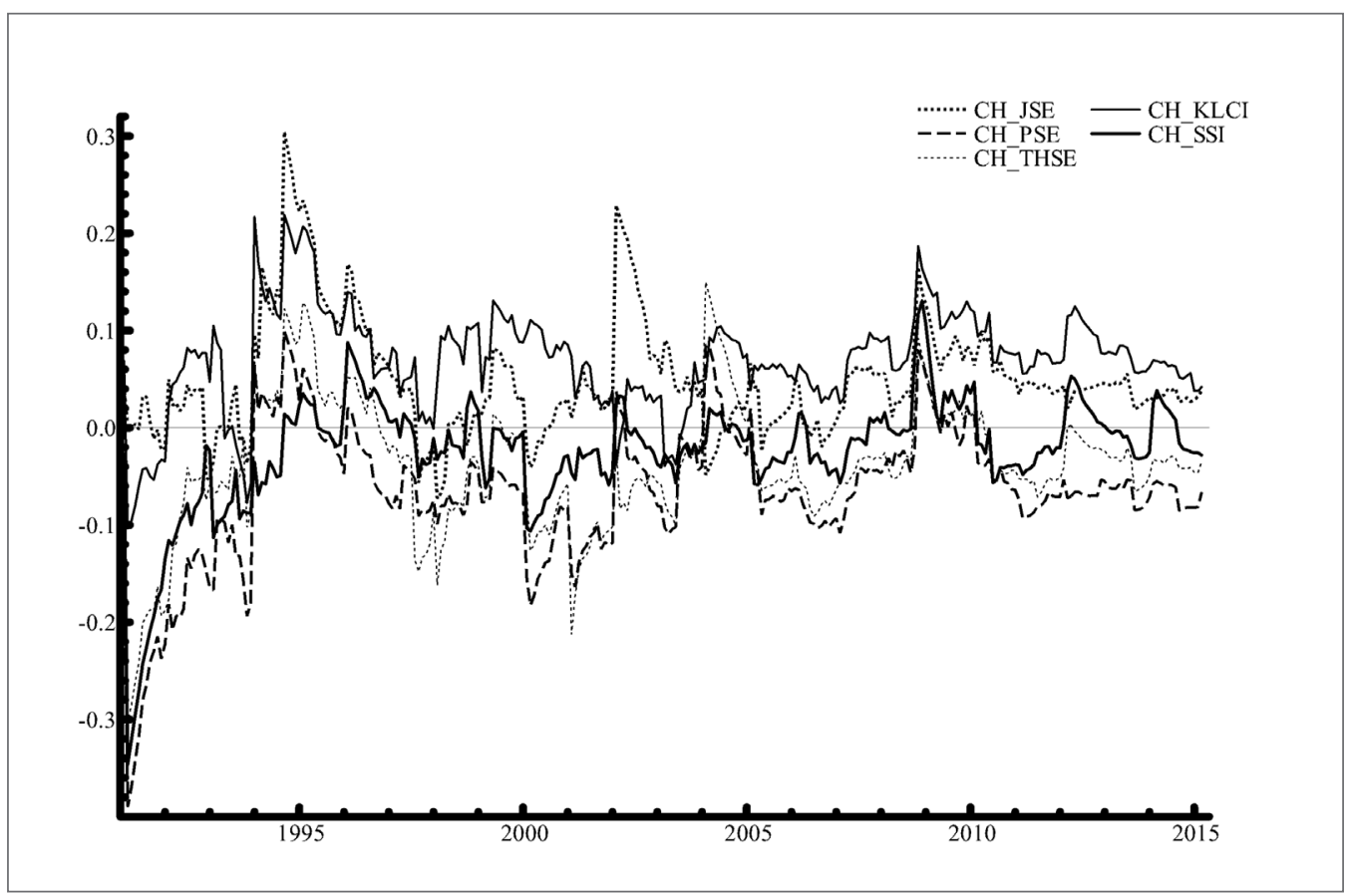

Figure 2. Dynamic Conditional Correlation between Stock Markets in ASEAN-5 and China's Economic Activities

To have a better picture of inter-regional correlation among ASEAN-5 stock markets with economic performance for China, the plots for their time-varying conditional correlations are illustrated in Figure 2. The DCCs were maintained at a level below 0.3 during the study period. At the beginning of the study period until 1994, most of the DCCs remained at a negative level, which implies that the ASEAN-5 stock markets and Chinese economies activities were inversely related. However, the DCC was increasing during pre-1994. However, in the post-1994 period, the DCC remained stable around the magnitude of $+/-0.1$ level with a slight downward trend. The trend remained relatively stable between the ASEAN-5 stock markets and Chinese economic activities with a sudden surge and fall. However, after 2009, there was a sudden change in the DCC movement to a sliding trend. Both the ASEAN-5 stock markets and Chinese economies activities move in opposite directions. This implies that if there were any slump in the ASEAN-5 stock markets, Chinese economic activities will continue to grow. On the other hand, even with a downturn in the Chinese economy, the stock markets in ASEAN-5 could still perform well. This reveals that the ASEAN-5 stock markets were suitable destinations for investors in China to diversify their financial portfolio for hedging purposes. 
Table 4. Bai and Perron Structural Break Dates for the Conditional Correlations

\begin{tabular}{ccccc}
\hline JSE-CH & KLCl-CH & PSE-CH & SSI-CH & THSE-CH \\
\hline Jul-94 & Jul-94 & Jul-94 & Jul-94 & Jul-94 \\
Feb-98 & & Feb-98 & Jan-99 & Feb-98 \\
& Feb-01 & Jan-02 & & Jun-03 \\
& Mar-07 & Sep-10 & Sep-07 & \\
\hline
\end{tabular}

To summarize, from the analysis of the time variant correlation, the estimated conditional correlations between stock markets and economic activities were relatively low with a few peaks and plunges. A weak correlation of below $30 \%$ between these two regions shows that they were less integrated. To further confirm the observed movements of DCC in Figure 2, it is necessary to identify the possible structural changes that occurred during that time to determine the actual structural break dates. To achieve this, the BP multiple structural break test was adopted.

\subsection{Perspective of Structural Change}

The source of structural change that happened in the conditional correlation among ASEAN-5 countries and China in July 1994 may have come from China because China's growth rate series fluctuated between $20 \%$ and $-20 \%$ with a volatility of $3 \%$ (see Figure 1 ), while the return series of the ASEAN-5 stock markets were relatively stable, with volatility below $2.5 \%$ for that time period. The detected date could be the aftermath effect of the unification of the exchange rate regime in China and the abolishment of the exchange controls on the current-account transactions that took place in April 1994. The move to full current account convertibility and the realization of the RMB convertibility under the current account was achieved in late 1996 (McKinnon and Schnabl, 2009).18 The success in this area stabilized the real economic growth in China while promoting a bilateral currency exchange between ASEAN and China. This economic event will impact ASEAN-5 and China concurrently.

The break dates on February 1998 and January 1999 for the conditional correlation between the ASEAN-5 stock market with the Chinese economic growth, except KLCI-CH, can be justified by a series of financial reform measures taken by the ASEAN- 5 government to revive the economy after the adverse effects of the Asian financial crisis.

The break dates observed on February 2001 and January 2002 for KLCI-CH and PSE-CH may be related to the dot-com bubble, which occurred during the stock market meltdown in 2000-2002. September 2000 is the starting point of the slump, where the internet boom was at its peak and the NASDAQ index was over 5000 points (Yu, 2004). This devastating stock market crash swirled in the impacted economies for approximately two years. The internet bubble in China expanded until the market became overheated during the meltdown of the internet bubble in the U.S. because the spillover of the U.S. internet boom to China was slower than the internet burst in the U.S. (Girardin \& Liu, 2007).

The break date between THSE-CH occurred in June 2003 coincided with the signing of the China-Thailand Free Trade Area (FTA) that took effect in October 2003. This agricultural goods agreement is an "early harvest agreement" with the aim to encourage the bilateral agricultural trade and enhance the welfare of the two nations.

The two breaks, in March and September-2007 for $\mathrm{KLCI}-\mathrm{CH}$ and SSI-CH, could be due to either the direct or indirect impact of the U.S. subprime mortgage crisis, which coincided with the U.S. recession (December 2007- June 2009). A similar result was observed in Lean and Teng (2013). As for the detected date, September 2010 for PSE-CH could correspond with the European sovereign debt crisis, which started at the end of 2009 and intensified beginning in early 2010 . 
Table 5. VAR Granger Causality Tests for Conditional Variances

\begin{tabular}{cc}
\hline Short Run Causality Direction & $\mathrm{CH}$ \\
\hline JSE & $\mathrm{J} \rightarrow \mathrm{C}^{* * *}$ \\
$\mathrm{KLCl}$ & $\mathrm{K} \leftrightarrow \mathrm{C}^{* * *}$ \\
PSE & $\mathrm{P} \leftrightarrow \mathrm{C}^{* * *}$ \\
SSI & \\
THSE & $\mathrm{T} \rightarrow \mathrm{C}^{* *}$ \\
\hline
\end{tabular}

Remarks: ${ }^{* *},{ }^{* *},{ }^{*}$ indicate significance at $1 \%, 5 \%$ and $10 \%$, respectively. Null hypothesis: The excluded variable does not Granger-cause the dependent variable. The best lag selection is automatic based on lag length criteria (AIC). For the full sample, the best lag is 12 .

Overall, the BP multiple structural break dates show that some of the breaks corresponded with the events in the countries, and some are related to global or regional events. This indicates that the countries examined experienced not only cross-country spillover effects but also the spillover effect from external shocks that affect both countries' correlation. Hence, it is worthwhile to further analyze the direction of the cross-country spillover effects between the ASEAN-5 stock market volatility and the Chinese economic activity volatility. This is important because the results will show whether the Chinese economic activity volatility influences the ASEAN-5 stock markets or vice versa. The findings will aid investors in deciding their future investment directions for portfolios.

\subsection{Volatility Spillover between ASEAN-5 Stock Markets and China's Economic Activities}

During the period of study, the Chinese economic activities were Granger-caused by the ASEAN-5 stock markets except for the Singapore stock return volatility. However, the influence of China's economic movements on ASEAN-5 stock markets' volatility was insignificant over the period of study except with regard to Malaysia and the Philippines' stock markets. The findings of this study are consistent with Valadkhani and Chen (2014), who found that the stock volatility of one country or region does influence the economic volatilities in another country or region. Similar conclusions were observed in studies by Schwert (1989; 1990), Hamilton and Gang (1996) and Ibrahim (2010). However, Tiwari et al. (2015) did not observe any bilateral causality between the stock market and economic activity, which contradict the findings of this paper.

Over the short term, fluctuations in Chinese economic activities only impacted Malaysia and the Philippines' stock volatilities. Hence, only Malaysia and the Philippines' stock markets displayed a bilateral causality relationship with Chinese economic activities. This implies that Malaysia and the Philippines' stock markets were more vulnerable to external economic shocks compared to other ASEAN-5 stock markets. This finding supports Tsouma's (2009) conclusion that the growth of the industrial production index influences stock returns in the emerging market.

As a conclusion, Singapore is a preferred destination for investors in China to diversify their asset portfolio and vice versa.

\section{Conclusion}

The purpose of this study is to explore the dynamic linkages between Chinese economic movement and ASEAN-5 stock markets using the time-variant framework and Granger causality tests. The aim is to identify the direction of the volatility spillover among the studied markets. This study also intends to detect the structural break dates observed between the ASEAN-5 stock markets and the Chinese economy, which are related to important facts and economic events. Last, the study attempts to review the equity diversification portfolio 
destination of China with ASEAN-5. Taken together, this study aims to uncover the possible deepening in the future regional economic integration in Asia.

The dynamic linkages between the ASEAN-5 stock markets with the economic conditions in China show that both regions were still weakly correlated between January 1991 and March 2015. These results imply that stock market movements in ASEAN-5 were not really being affected by the economic conditions in China. Another important finding is that the DCC between ASEAN-5 and China dropped noticeably during the Asian financial crisis, the collapse of the internet bubble and the subprime crisis. The observed dates from the BP multiple structural break test further supports the observation in DCC movements. Most of the observed dates coincided with China's economic reforms, together with the FTAs' conclusion and some major economic crises (1997 Asian financial crisis, collapse of the internet bubble, the subprime crisis and the European sovereign debt crisis). Another observation from this study is that shocks emanating from Chinese economic movements had no influential effects on ASEAN-5 stock markets volatilities except with regard to Malaysia and the Philippines, whereas China's economy was influenced by the volatility of ASEAN-5 stock markets except Singapore.

Overall, this study concluded that the stock volatility of ASEAN-5 with the economic activities in China still remained at a very low level, and diversion among these regions was observed during times of financial turbulence. The results based on the DCC-MGARCH model have confirmed the conjecture that ASEAN-5 had gradually stood out as a preferred destination for the international portfolio diversification for Chinese investors, except for Malaysia and the Philippines. On the other hand, China has become the preferred portfolio diversification area for investors in Singapore to diversify their investment portfolio.

The empirical findings also support the idea that ASEAN-5 governments should implement suitable economic policies and monitor the financial development that has been taking place in China. Combined with prudent portfolio diversification management, this would help minimize volatility in the financial portfolio. Policy makers should also attract the participation of large foreign institutional investors into the ASEAN-5 stock markets, especially those with rela- tively low correlation with ASEAN-5 stock markets and those that are less volatile or do not coincide with any financial crisis in the ASEAN-5 stock markets such as China. All these suggestions should be favorable in cushioning stock market volatility and improving market discipline in the ASEAN-5 stock markets.

These findings offered important implications for investors, portfolio managers, policymakers, and leaders in ASEAN and China. Hence, it is wise for ASEAN leaders to pursue market-based integration with China rather than an institutional-based integration. It is also not recommended for ASEAN to push forward with economic integration with the Eurozone due to its current debt crisis.

\section{References:}

Arouri, M. H., \& Nguyen, D. K. (2009). Time-varying characteristics of cross-market linkages with empirical application to Gulf stock markets. Managerial Finance, 36(1), 57-70.

Bai, J. \& Perron, P. (2003). Computation and analysis of multiple structural change models. Journal of Applied Econometrics, 18(1), 1-22.

Bekaert, G. \& Harvey, C. R. (1997). Emerging equity market volatility. Journal of Financial Economics, 43(1), 29-77.

Bekaert, G. \& Harvey, C. R. (2002). Research in emerging markets finance: Looking to the future. Emerging Markets Review, 3(4), 429-448.

Bekaert, G., Harvey, C. R., \& Lumsdaine, R. L. (2002). Dating the integration of world equity markets. Journal of Financial Economics, 65(2), 203-247.

Berben, R. P. \& Jansen, W. J. (2005). Comovement in international equity markets: A sectoral view. Journal of International Money and Finance, 24(5), 832-857.

Bollerslev, T. \& Wooldridge, J. (1992). Quasi-maximum likelihood estimation and inference in dynamic models with time-varying covariances. Econometric Reviews, 11(2), 143-172.

Bollerslev, T. (1986). Generalized autoregressive conditional heteroskedasticity. Journal of Econometrics, 31(3), 307-327.

Candelon, B., Piplack, J., \& Straetmans, S. (2008). On measuring synchronization of bulls and bears: The case of East Asia. Journal of Banking \& Finance, 32(6), 1022-1035. 
Engle, R. F. (1982). Autoregressive conditional heteroskedasticity with estimates of the variance of UK inflation. Econometrica, 50(4), 987-1008.

Engle, R. F. (2002). Dynamic conditional correlation - a simple class of multivariate GARCH models. Journal of Business and Economic Statistics, 20(3), 339-350.

Forbes, K. J. \& Rigobon, R. (2002). No contagion, only interdependence: measuring stock market comovements. Journal of Finance, 57(5), 2223-2261.

Gilmore, C. G., \& McManus, G. M. (2002). International portfolio diversification: US and Central European equity markets. Emerging Markets Review, 3(1), 69-83.

Girardin, E., \& Liu, Z. (2007). The financial integration of China: New evidence on temporally aggregated data for the A-share market. China Economic Review, 18(3), 354-371.

Goetzmann, W. N., Li, L., \& Geert Rouwenhorst, K. (2001). Long-term global market correlations (Working Paper No. 8612). National Bureau of Economic Research. Retrieved from http://www. nber.org/papers/w8612

Gregory, A. W. \& Hansen, B. E. (1996). Tests for cointegration in models with regime and trend shifts. Oxford Bulletin of Economics and Statistics, 58(3), 555-560.

Guillaumin, C. (2009). Financial integration in East Asia: evidence from panel unit root and panel cointegration tests. Journal of Asian Economics, 20(3), 314-326.

Gupta, R. \& Donleavy, G. D. (2009). Benefits of diversifying investments into emerging markets with time-varying correlations: An Australian perspective. Journal of Multinational Financial Management, 19(2), 160-177.

Gupta, R., \& Guidi, F. (2012). Cointegration relationship and time varying co-movements among Indian and Asian developed stock markets. International Review of Financial Analysis, 21, 10-22.

Hamilton, J. D., \& Gang, L. (1996). Stock market volatility and the business cycle. Journal of Applied Econometrics, 11(5), 573-593.

Harvey, C. R. (2000). Drivers of expected returns in international markets. Emerging Markets Quarterly, 4(3), 32-48.

Hassan, M. K. \& Naka, A. (1996). Short-run and longrun dynamic linkages among international stock markets. International Review of Economics \& Finance, 5(4), 387-405.
Hooy, C. W. \& Goh, K. L. (2010). Exposure to the world and trading-bloc risks: A multivariate capital asset pricing model, Research in International Business and Finance, 24(2), 206-222.

Huang, B. N., Yang, C. W., \& Hu, J. W. S. (2000). Causality and cointegration of stock markets among the United States, Japan and the South China Growth Triangle. International Review of Financial Analysis, 9(3), 281-297.

Ibrahim, M. H. (2010). An empirical analysis of real activity and stock returns in an emerging market. Economic Analysis and Policy, 40(2), 263-271.

Jones, C. P., Walker, M. D., \& Wilson, J. W. (2004). Analyzing stock market volatility using extreme day measures. Journal of Financial Research, 27(4), 585-601.

Johnson, R. \& Soenen, L. (2003). Economic integration and stock market comovement in the Americas. Journal of Multinational Financial Management, 13(1), 85-100.

Kasa, K. (1992). Common stochastic trends in international stock markets. Journal of Monetary Economics, 29(1), 95-124.

Laopodis, N. T. (2005). Portfolio diversification benefits within Europe: Implications for the US investor. International Review of Financial Analysis, 14(4), 455-476.

Lean, H. H., \& Teng, K. T. (2013). Integration of world leaders and emerging powers into the Malaysian stock market: A DCC-MGARCH approach. Economic Modelling, 32, 333-342.

Lim, L. K. (2009). Convergence and interdependence between ASEAN-5 stock markets. Mathematics and Computers in Simulation, 79(9), 2957-2966.

Lucey, B. M., \& Muckley, C. (2011). Robust global stock market interdependencies. International Review of Financial Analysis, 20(4), 215-224.

Majid, M. S. A., Meera, A. K. M., Omar, M. A., \& Aziz, H. A. (2009). Dynamic linkages among ASEAN-5 emerging stock markets. International Journal of Emerging Markets, 4(2), 160-184.

Marashdeh, H.A. (2006). Financial integration of the MENA emerging stock markets (Unpublished doctoral dissertation). University of Wollongong, Wollongong, Australia

Markowitz, H. (1952). Portfolio selection. The Journal of Finance, 7(1), 77-91. 
Masih, A. M. M., \& Masih, R. (1999). Are Asian stock market fluctuations due mainly to intra-regional contagion effects? Evidence based on Asian emerging stock markets. Pacific-Basin Finance Journal, 7(3-4), 251-282.

McKinnon, R. \& Schnabl, G. (2009). China’s financial conundrum and global imbalances (Working Paper No. 277). Bank for International Settlements. Retrieved from http://www.bis.org/publ/work277.pdf

National Bureau of Statistics of China (2012, February 22). Statistical Communiqué on the 2011 National Economic and Social Development. Retrieved from http://www.stats.gov.cn/english/NewsEvents/201202/t20120222_26575.html

Nguyen, D. K. \& Bellalah, M. (2008). Stock market liberalization, structural breaks and dynamic changes in emerging market volatility. Review of Accounting and Finance, 7(4), 396-411.

Pagan, A. R. \& Harding, D. (2002). Dissecting the cycle: a methodological investigation. Journal of Monetary Economics, 49(2), 365-381.

Phengpis, C. \& Swanson, P. E. (2006). Portfolio diversification effects of trading blocs: The Case of NAFTA. Journal of Multinational Financial Management, 16(3), 315-331.

Plummer, M. G. \& Click, R. W. (2005). Bond market development and integration in ASEAN. International Journal of Finance \& Economics, 10(2), 133-142.

Savva, C. (2009). International stock markets interactions and conditional correlations. Journal of International Financial Markets, Institutions \& Money, 19(4), 645-661.

Schwert, G. W. (1989). Business cycles, financial crises, and stock volatility. Carnegie-Rochester Conference Series on Public Policy, 31(1), 83-125.

Schwert, G. W. (1990). Stock returns and real activity: A century of evidence. Journal of Finance, 45(4), 1237-1257.

Sohel Azad, A. S. M. (2009). Efficiency, cointegration and contagion in equity markets: Evidence from China, Japan and South Korea. Asian Economic Journal, 23(1), 93-118.

Syriopoulos, T. (2011). Financial integration and portfolio investments to emerging Balkan equity markets. Journal of Multinational Financial Management, 21(1), 40-54.
Teräsvirta, T. (2006). An introduction to univariate GARCH models (Working Paper No. 646). Stockholm School of Economics. Department of Economic Statistics.

Tiwari, A. K., Mutascu, M. I., Albulescu, C. T., \& Kyophilavong, P. (2015). Frequency domain causality analysis of stock market and economic activity in India. International Review of Economics \& Finance, 39, 224-238.

Tse, Y. K. (2000). A test for constant correlations in a multivariate GARCH model. Journal of Econometrics, 98(1), 107-127.

Tsouma, E., 2009. Stock returns and economic activity in mature and emerging markets. The Quarterly Review of Economics and Finance, 49(2), 668-685.

Valadkhani, A., \& Chen, G. S. (2014). An empirical analysis of the US stock market and output growth volatility spillover effects on three AngloSaxon countries. International Review of Applied Economics, 28(3) 323-335

Vo, V. X., \& Daly, K. J. (2005). European equity markets integration - implications for US investors. Research in International Business and Finance, 19(1), 155-170.

Yu, I. W., Fung, K. P., \& Tam, C. S. (2010). Assessing financial market integration in Asia - Equity markets. Journal of Banking \& Finance, 34(12), 28742885.

Yu, T. S. (2004). Can East Asia rise again. In C. Wiemer \& H. Cao (Eds.), Asian economic cooperation in the new Millennium: China's economic presence (Vol. 1, pp. 197-211). Singapore: World Scientific Publishing. 


\section{Endnotes}

1 National Bureau of Statistics of China (2012, February 22)

2 ASEAN-5 consists of five nations: Indonesia, Malaysia, Singapore, Thailand and the Philippines.

3 Detailed sourced from Economic Cycle Research Institute, available at http://www.businesscycle.com/ ecri-business-cycles/international-business-cycledates-chronologies

4 All indices are extracted from DataStream. The indices are denominated in local currency to avoid the impact of the exchange rate volatility on the stock market linkages. The intention of this study is to analyse the stock market linkages that happened naturally among countries without being affected by the fluctuation of exchange rates (Berben \& Jansen, 2005; Goetzmann, Li, \& Geert Rouwenhorst, 2001; Johnson \& Soenen, 2003; Lucey \& Muckley, 2011; Plummer \& Click, 2005). All indices are seasonally adjusted using the Census X-12 filter. Four multivariate models are formed to discuss the interdependency between the ASEAN-5 stock markets and Chinese economic condition.

5

6 The growth rate of the IPI is used to measure the relative degree of fluctuation in economic activities.

7 Most studies typically assume that the errors of the return series either follow an AR(1) or the first order moving average, $M A(1)$ process. The results are available upon request.

$8 R t$ of the DCC model is different from the CCC model as Rt of the CCC model is time-invariant.

9 The time-decaying and mean-reverting GARCH model means that the conditional variance does not persist over time but slowly moves toward the longrun mean level at the rate recommended by the sum of $\alpha_{i}$ and $\beta_{i}$.

10 Positive covariance implies that the tested variables are strongly linked and move in the same direction and vice versa.

11 QML is maximum likelihood with a robust variance-covariance estimator.

12 The conditional correlation is generated from the DCC-MGARCH model discussed in the previous section.

13 It is not advisable to model the return series as in- dependent and identically distributed over time because the return series are actually interdependent with the increase of data frequencies (Teräsvirta, 2006). This makes volatility a better measure for stock market risk compared to stock market returns and the standard deviation of stock returns (Jones, Walker, \& Wilson, 2004)

14 The Granger causality test is performed using EVIEWS 7.

15 The results are available upon request.

16 ASEAN-5 and the reference country are tested as a group of six countries.

17 Investors who wish to avoid large, erratic swings in portfolio returns may wish to structure their investments to produce a leptokurtic distribution.

18 By December 1, 1996, China had formally fulfilled the International Monetary Fund's Article 8 from the Agreement on International Currencies and Funds on current account convertibility. 